\title{
Managing Sustainable Development and Poverty Alleviation in the Islamic World
}

The Centre for Poverty and Development Studies (CPDS), Faculty of Economics and Administration, University of Malaya, hosted an international conference, "Managing Sustainable Development and Poverty Alleviation in the Islamic World," on 14-15 October 2008 in Kuala Lumpur, Malaysia. This event attracted around 100 participants and eighteen presenters.

The thematic foci reflected the understanding that the Islamic world exhibits significant and disturbing variations in its levels and magnitudes of socioeconomic development, poverty incidence and prevalence, income distribution patterns, literacy, employment, and economic growth. As these are inconsistent with Islam's principles and ethics of distributive justice and equity, unity, and social responsibility, Muslim researchers and concerned individuals must join the quest to devise concerted and collaborative Islamic solutions to the challenges of sustainable development, as well as of poverty alleviation and eradication, in the Islamic world.

Within an Islamic framework, the presenters analyzed poverty as a socioeconomic phenomenon from multiple perspectives. One perspective justifies the instrumentality of empowerment in overcoming poverty in Islamic societies. As the poor are powerless, the universal principles of equality and justice imply a more equitable power distribution in society, and collective social action implies consultation strategies to resolve social imperfections. In Malaysia's three poverty-focused organizations, empowerment was analyzed using a framework of determinants, including trusting the organizer, local working culture, participants behaving like friends, the government's role, importance of the organization, belief in and trusting the organization, and roles at all levels. It was established that individuals, the community, and the organization widely acknowledge empowerment as a significant determinant for success.

A more holistic approach framed sustainable development and poverty eradication in a globalizing world. Sustainability relates to environmental, political, and socio-political parameters (the United Nations), which finds its counterparts in the shuratic process (Qur' an 55:5-25 and 2:30) and the concepts of daruriyat, hajiyat, and tahsiniyat, among others. Several Islamic juridicial principles relevant to environmental sustainability can thus be derived and underpin sustainable policy interventions. Poverty alleviation in 
Islam focuses on the faqir and miskin segments primarily through human resource development, providing employment opportunities, and operating the welfare-oriented institutions of zakat and bayt al-mal. Globalization is not inherently unacceptable, although its consequences are tangible and have to be - and can be - confronted using Islamic interventions based on the Qu'ran. Malaysia and Yemen were cited as examples, although there were no explicit references to the underlying Islamic philosophy and principles driving their broad state-driven sustainability and poverty eradication strategies.

Malaysia's experiences of $a w q a f$, zakat, and waqaf were highlighted in two papers as examples of Islamic poverty alleviation interventions within the state-instituted Islamic regulatory framework. While the institutional goals are noble and humanitarian, the regulatory framework and its associated implementation mechanisms and capabilities require more effective redesigning to reach out to the Islamic poor.

Four sessions explored topics with wider ranging ramifications. The session on capacity building to underpin the efforts at sustainable development focused primarily on Malaysia's experience with education. One presentation analyzed the linkages between investments in the public educational infrastructure and broad economic growth on the premise that human capital investment yields the greatest long-term returns. The major determining variables identified were enhancements in educational quality, free primary and secondary education, an expanding tertiary sector, adult education, and a sensitivity to gender education.

The second contribution investigated the profile of Islamic theology graduates in Malaysia, which has invested significantly in Islamic education at all levels. In 2007, the majority of these graduates (1,543 out of 1,772) obtained first degrees, while 190 and 39 graduated with an M.A. and a $\mathrm{Ph} . \mathrm{D}$., respectively. The respondents of the 2007 tracer survey showed that of the 40 percent reporting employment, all indicated professional or technical jobs with an even distribution between public and private sector employment.

Micro-finance attracted the attention of two researchers, the first of whom dealt with theoretical possibilities of transforming the decreasing partnerships (musharakah mutanaqisah) structure for micro-financing. The author's core point was that Islamic principles should be more closely adhered to in micro-financing by refining decreasing partnerships so that they will be in alignment with the Islamic ideals of fairness and equitable treatment for all parties. The second paper assessed the effectiveness of microcredit loans to alleviate poverty among the poorest segments by Amanah Ikhtiar Malaysia (AIM), a prominent NGO established in 1987. The authors 
stressed that AIM's success is predicated upon its reasonable financing terms and the active government support provided for its programs.

From a different perspective, the case was made for Sudan's Islamic banking structure to exploit the benefits that investments in computer-based financial information (CBIS) systems can accrue to the banking sector exceeding the investment costs and training inputs required. The major application areas include financial accounting, bank transactions, reporting, E-gabi (software for opening customer accounts and facilitating inter-bank transactions), micro-link, and Banxware/Orabank (software for Islamic banking). The survey of Sudanese banks revealed a major stumbling block in the lack of an efficient infrastructure to implement CBIS, insufficient training inputs, fear of job losses through computerization, and computer illiteracy, although general acknowledgement of its broad benefits is not denied.

The session on "Family and Gender Issues" began with a broad approach to these topics without specific reference to Islamic communities. The statistics cited emphasized that social, cultural, and family factors determine and consolidate gender differences. Significantly, gender inequality and disparities are constant features of daily life in developing countries. The case was made for a greater sensitization to gender inequalities, recognizing that both sexes are partners in development and should benefit equally from it.

Decision-making power by women in Muslim households in Malaysia extrapolated the first presentation by investigating their influence on family matters, reproductive health and rights as part of a subsample of a national 2005 study on the same topics in Malaysia. A high proportion (64\%-89\% of the sample of 1,236 married Muslim women, aged 25-59 years, more urban than rural based, more not working than employed) were sympathetic to making decisions on whether or not to have children, number of offspring, how to support and raise them, their children's education, contraceptive use and the preferred method, and joint decision making in purchasing land, a house, and a car.

Two other presentations examined poverty, resource use and good governance in OIC countries, and Islam and the dynamics of proselytizing in the global village. The first paper revealed that poverty alleviation and resource management have not been encouraging across the OIC world largely due to resource endowment disparities, inconsistent governance quality, and the spirit of non-sharing and lack of solidarity. How Islamic solidarity could then be expressed is in institutionalizing zakat administration; intensifying trade for the poor; intensifying multilateral cooperation in member countries; adopting arbitration followed by persuasion, coercion, and conflict res- 
olution; and having a standing, quick-response army. Proselytizing in the global village is predicated upon the influence of the information age in deepening one's own religious understanding while simultaneously developing a greater sensitivity for other religious beliefs.

L. J. Fredericks Senior Visiting Research Fellow, Centre for Poverty and Development Studies

Faculty of Economics and Administration University of Malaya, Kuala Lumpur, Malaysia 